International Journal of Instruction

e-ISSN: 1308-1470 • www.e-iji.net
July $2019 \bullet$ Vol.12, No.3

p-ISSN: 1694-609X

pp. 237-252

Received: 13/12/2018

Revision: 25/03/2019

Accepted: 31/03/2019

OnlineFirst:26/04/2019

\title{
The Effect of a Structured Playfulness Program on Social Skills in Kindergarten Children
}

\section{Paschalio Loukatari}

School of Physical Education and Sport Sciences of Democritus University of Thrace, Greece,p.loukatal@gmail.com

\section{Ourania Matsouka}

School of Physical Education and Sport Sciences of Democritus University of Thrace, Greece, oumatsou@phyed.duth.gr

\section{Katerina Papadimitriou}

School of Physical Education and Sport Sciences of Democritus University of Thrace, Greece, kpapadim@phyed.duth.gr

\section{Semina Nani}

School of Physical Education and Sport Sciences of Democritus University of Thrace, Greece, snani@phyed.duth.gr

\section{Vasilis Grammatikopoulos}

Department of Preschool Education of University of Crete, Greece, gramvas@uoc.gr

The purpose of this study was to examine the effect of a structured, playful activity program on the development of social skills in kindergarten children during break time in the schoolyard. Twenty eight boys and thirty two girls aged from 5 to 6 years old consisted the sample of the present study. The participants were randomly divided into two groups the treatment and the control group respectively. The experimental group participated in a 4 weeks playful program while control group didn't participate in any kind of structured activity. Data were gathered through observations and videotaped recordings of the students in the schoolyard during breaks. The researcher coded children's behaviours from video recordings and completed the Social Skills Rating System (SSRS) for each child, before and after interventional program. Results demonstrated that there was statistically significant difference between the degree of development in students' social skills during breaks and their participation in a structured programme of playful activities in the schoolyard.

Keywords: social skills, kindergarten, intervention, outdoor play, schoolyard

Citation: Loukatari, P., Matsouka, O., Papadimitriou, K., Nani, S., \& Grammatikopoulos, V. (2019). The Effect of a Structured Playfulness Program on Social Skills in Kindergarten Children. International Journal of Instruction, 12(3), 237-252. https://doi.org/10.29333/iji.2019.12315a 


\section{INTRODUCTION}

Recent social development theories suggest that play provides an opportunity to children to practice different social roles and learn social rules (Stagnitti, 2004, Bodrova and Leong, 2015). When children have been deprived from the chance to play and are given the opportunity, then they recover such skills (Pellegrini and Bohn, 2005), since chronic lack of playing during the critical period from birth to seven years old, leads to a lack of social skills and aggressive behavior (Hughes, 2003). Play is influenced by adult intervention in the natural and social environment of young children, by providing a predictable but flexible framework in which interventions may be repeated and extended (Moss et al., 2002) and determined through the dimensions of time, space and place (Scarlett et al., 2005). Many studies indicate that children, during transition from early childhood age (preschool and elementary school) to secondary education, value free time for playing, in contrast to the predominant character of adult supervision during the school day (Corsaro and Molinari, 2005; Devine, 2002; MacDougal et al., 2004).

Children should enjoy at least three hours of play daily, at different times, with one hour involving outdoor games (Miller \& Almon, 2009) in an all-day kindergarten. Outdoor playing in kindergarten is associated with a break and time for relaxation, providing various privileges to the children (physical, emotional, social, cognitive) as they are given the opportunity for recreation and fun. It is the time within the daily schedule, during which students disengage from school work rest (Lee et al., 2007; Rasberry et al, 2011), play, run and develop social skills (Pellegrini, 2006). The relaxation time offers students the opportunity for social interaction (McCambridge et al., 2006), as during play they learn to negotiate, collaborate, share and solve problems (Sibley and Etnier, 2003) also support their opinion and control themselves (Bjorklund and Brown, 1998).

Nonetheless, in contemporary societies, due to the fast pace of everyday life and modern lifestyle, a decrease is observed in free play during children's leisure time both at home and at school. The prevailing view on the free play of children is that it has moved from public spaces such as streets, playgrounds and the courtyards of schools to primarily indoors for mainly engagement with technology such as television, video and computer games (Buckingham, 2000). Doliopoulou and Rizou (2012) ascertained that there is a significant absence of team games in Greek kindergartens, coupled with an aggressive behavior in preschool children, possibly as a result of the modern lifestyle. The same survey reflected conflicting views among parents, some of whom seemed to be concerned about their children's overexposure to television and the computer, while others were concerned about the dangers of playing outdoors. In addition, teachers and parents agree that due to the lack of time, preschool children are more used to playing indoors with computer games, with the effect of becoming more competitive and reluctant to share their toys, while often expecting adults to resolve their differences.

Scientific research has been directed towards the development of social skills among preschool children through effective interventions, considering play at its main axis (Rosenthal, 2003). The development of social skills in childhood is an area of interest for researchers and a global concern for parents, especially given the undeniably 
constructive role of social skills in shaping adaptive capacity from early childhood to adolescence (Rosenthal, 2003). Social skills are mainly based on the behavior that individuals wish to perfect in order to participate successfully in different social contexts such as withstanding peer pressure from individuals or groups, requesting assistance and resolving conflict situation (Greene, 2003). Also, social skills are related to their acceptance by their peers, their emotional health and their ability to create interpersonal relations show evidence of social adaptation. Children who are sociable, cooperative and friendly are more likely to succeed both in the social and academic school context (Gouley et al., 2008), while children lacking social skills usually exhibit behavioral problems (Langeveld et al., 2012).

Social skills are acquired mainly through learning processes including observation, modeling, testing and receiving feedback, as they also refer to specific, developmentally appropriate verbal and non-verbal behaviors that are effective in the initiation, maintenance and termination of interpersonal interactions (Cartledge and Milbum, 1995). They are influenced by the characteristics, requirements and expectations encountered in specific environments and, furthermore, the assessment of social skills aims to identify and therefore design intervention programs (DuPaul and Eckert, 1994). Also, it is clear that early detection and intervention in children's social skills in a significant way reduces the subsequent social cost and increases the effectiveness of interventions. Considering these facts, it becomes clear that studying their developmental inclinations through systematic intervention and early evaluation, longterm effects on their mental health (Grammatikopoulos, 2012; Trevlas et al., 2003) and their school adjustment can be determined.

Furthermore, there is evidence worldwide of the positive effects in young children through participation in physical activity programs outside the school framework. Researchers conclude that high quality structured out-of-school time physical activity programs create suitable surroundings that support and promote social benefits in children for the following reasons: (a) they are conducted in safe settings, (b) they prevent children from being involved in delinquent activities, (c) they teach them general and specific skills, attitudes and behaviors, (d) they provide them with opportunities to interact with other peers and adults (Trevlas et al., 2003). In kindergarten, children's social life is arranged by teachers within the school environment while outside school their social life depends largely on their parents' wishes, daily routine and available resources (Schneider et al., 2000). Younger children rely heavily on their parents' involvement in order to develop both fellowships with other peers and social skills outside the kindergarten (Bhavnagri and Parke, 1991). Ladd and Hart (1992) provided evidence to the fact that the parents' involvement in young children's activities is associated with high levels of social behavior in their children, greater acceptance of their peers (especially among boys) and less frequent occurrence of antisocial behaviors. Parental guidance may include facilitation of non-organized meeting opportunities with other peers (playful activities after school) or their participation in more structured and organized sports activities. The participation in sports activities outside the school framework contributes to a range of benefits for 
young children, such as improving their relationships, boosting their confidence and reducing anxiety (Smith, 2003).

\section{The Aim of the Study}

The purpose of this study is to assess the social skills of kindergarten children (aged 5-6 years) and to examine the effect of a playful activity structured program on the development of students' social skills during break time in the schoolyard.

\section{METHOD}

\section{Population and Sampling}

A total of 106 kindergarten children from two public kindergartens were approached in order to participate in the study however, 36 students did not meet with their parents approval for the participation in the project. Furthermore, 10 of the 70 students ( 7 boys and 3 girls) were considered as an available sample and they randomly formed the pilot group of the measurement scale in order to investigate its reliability by observing the students during free play through the method of videotaping. The above preliminary procedures affected the sample and its final form consisted of a total of 60 examinees ( 28 boys and 32 girls). The children's age ranged from 60 to 72 months, their nationality was Greek and their intelligence average. Parental permission was requested for children's involvement in the study and the approval for the conduction of this survey was granted by the Directorate of Primary Education Studies, Department A, Implementation of Programs for Educational Policy Institute.

\section{Data Collection Tools}

The rating scale used in this study was Social Skills Rating System/Social Skills Questionnaire/ Elementary Level (Grades K-6)/Teacher Form (Gresham \& Elliott, 1990). This form has been adapted to preschoolers while the methodology tool SSRS was evaluated by Han and his colleagues (2005) as a reliable and useful tool in educators' research methods. Internal consistency of the SSRS was evaluated for the assessment of the students' performance in social skills (Mckevitt and Elliott, 2005). Unstructured observations were recorded through videotaped and then analyzed. This method involves the collection of large amounts of information since there are few restrictions. In the assigned study, the researcher records qualitative data using structured observations. A tool, in this case, a checklist, is used by the researcher to record the social and behavioral skills under study, by ticking off the item as it is demonstrated during school breaks. This systematic observation minimizes, possibly eliminates, the variations that might arise from different observers and facilitate categorization (Bell, 2005). It makes data collection more straight forward, limiting subjectivity and observer bias, while enhancing validity and reliability (Gerrish and Lacey, 2010). The measurement scale SSRS was back to back translated in Greek version by academicals experts. The reliability and validity of the SSRS has been examined in large sample of students and has been shown its concurrent and converging validity (Fox and Boulton, 2005; Reiter and Lapidot-Lefler, 2007; Kokkinos and Antoniadou, 2013). In the present study the scale had a high Cronbach Alpha of 0.83, 
while no factorial analysis was used, as according to the manufacturers' statements, some statements correspond to more than one scale at the same time. The 48 criteria of the scale are related to 2 areas: 1. Social Skills concerned with the factors of (a) cooperation, (b) assertion, (c) self-control and 2. Behavioral Problems dealing with the factors of (a) externalizing, (b) internalizing and (c) hyperactivity.

A 3-point Likert scale (where $0=$ never and 2=very often) was used for SSRS evaluation.

\section{Procedure and Data Collection}

Before the SSRS evaluation and the videotaping process, the researcher organized four preliminary meetings (a total of 8 hours) with the 7 members of the kindergartens' teaching staff in order to clarify the purpose of the research process. During the same period some information was collected from the teaching staff of the 2 schools in order to complete the first part of the questionnaire and in addition, to register students with special needs. It needs to be noted that in the survey participated, only students who were no attending with some form of disability diagnosed by a State Child Guidance Clinic. Furthermore, a preliminary investigation was also held, in which preschoolers' parents were requested to complete a short questionnaire regarding their children's participation or not, in any out-of-school time (OST) physical activity. The above procedure was carried out early in the afternoon for the all-day classes and early in the midday for the morning classes, by collecting data on the spot.

Table 1

Students' Demographic Characteristics $(\mathrm{N}=60)$

\begin{tabular}{llll}
\hline \multirow{2}{*}{ Groups $(\%)$} & \multicolumn{3}{c}{ Sex $(\%)$} \\
\cline { 2 - 4 } & Boys & Girls & Total \\
\hline Treatment group & 53.3 & 46.7 & 50 \\
\hline Control group & 40 & 60 & 50 \\
\hline Total & 46.7 & 53.3 & 100 \\
\hline
\end{tabular}

In the initial measurement, over the period of two weeks, the students were videotaped during their free play in the schoolyard. It took 15 to 20 minutes for each student to complete the SSRS form. To be noted that video recording data process was a repetitive process during which the researcher, in order to provide an accurate evaluation of the students' social skills level, was observing two children at a time.

\section{The Structure of the Intervention Playful Activity Program}

From the 3rd to the 6th week of research procedure, the intervention program was carried out through the planning of four daily shots with their sequential application every 1st week of intervention on three different days (for the 3 subgroups of the experimental group) and for the total of 4 weeks. Each plan corresponded to one weekly intervention and the treatment group participated in a collaborative playful activity program through the formation of small groups (per ten) or by forming pairs in the schoolyard. The main axis of the project involved some traditional games through numbered markings on the ground, the placement of a rubber at a fixed reference point 
and recyclables with no educational value (car tires, hoops connected to the trunk of a tree).

The materials were easily handled by children and at each intervention preschoolers pointed different ways of using the equipment were indicated. Before the implementation time, the students participated in communication games through the formation of a cycle at the schoolyard in order to familiarize themselves with the other classmates. Then, the researcher motivated the children by using flashcards in which some games were depicted. The children had to decode the pictures and connect them to the respective games that were located in the courtyard as if it were 'hidden treasure'.

\section{Content of the Playful Activity Intervention Program}

The playful activity project aimed to develop social skills and improve certain behavioral problems. It included four sections and was focused on the following themes: (1) children's transition from individuality to duality, (2) observance of the rules for turn-taking and emotional control of children, (3) children learn to play and communicate with each other (4) acceptance of others, mutual help, trust, responsibility, participation, gaining self-confidence and improvisation.

Unit 1: Children's transition from individuality to duality

In this section the game "The giant's hoops" was implemented with the help of colored car tires and as a motive a storytelling technique was used to spark the interest of children. Then, led by the researcher, the children imitated some animals and under the sound of musical instruments (maracas, tambourine) they ran around the tires. With the cessation of the musical instruments the children first had to get individually inside the tires which corresponded to the number of children and symbolized their nests. Then, the researcher gradually removed some tires and encouraged the children to discover different ways to fit in a tire in groups of two or three (e.g. to embrace in the tire).

Unit 2: Observance of the rules for turn-taking and emotional control of children

This section included the play "The lake with the ducks" and similarly with the previous section the researcher used the technique of narrating a short story. The game consisted of numbered lanes on the ground and was a variation of the traditional game "hopscotch". During the implementation of the game the preschoolers in turns had to follow certain rules so as to be able to cross the designed path hopscotching within those 7 blocks, the 3 relaxation areas (lakes with ducklings) and the semicircle (grass). According to the rules of the game, children with the help of a stone had to target in turns the numbered stone blocks without having the stone stop outside the lanes or the rest areas, whereas in case of failure they lost their turn. Hence, they practiced to accept feelings of sadness as well as to control their anger through verbal encouragement given by the researcher who allowed them trying again in accordance with the rules for taking turns.

Unit 3: Children learn to play as a team and communicate 
This section included the game "Hoop" which had a team-cooperative nature, as with the help of a ball the children first, by forming a row and passing the ball to each other, from hand to hand and then by forming a tunnel with their feet, had to cooperate in such a way that the ball did not fall down or deviate from the planned route (under feet, etc.), with the ultimate goal to reach the basket. The game ended when all children from the first until the last player had completed at least one attempt.

Unit 4: Acceptance of others, mutual help, trust, accountability, participation, gaining self-confidence and improvisation ability

This section included a game with elastic material which was placed in the covered schoolyard area (gazebo).The pre-schoolers encouraged by the researcher had to choose a classmate to form a couple with, in order to reproduce certain kinetic patterns in pairs and to follow certain rules, using mutual assistance and proper coordination. The procedure was repeated in order to create different multiple pair combinations each time, therefore involving all the children and promoting the acceptance of their peers.

The games mentioned above (both as tools and as equipment) were the researcher's methodological tools for the development of the students' social skills. The students, however, used the equipment in various ways, thus demonstrating their creativity during their free play. They were divided in small groups of 10 students with multiple combinations within the kindergartens' timetable. This program took place 3 times a week for $30 \mathrm{~min}$ per session. This process demanded the pre-schoolers' disengagement from their daily spontaneous noon-time activities in the class. The control group followed the typical kindergarten program of spontaneous play and interaction.

The final measure of the social skills of preschoolers was held on the 7 th and the 8 th week of research by videotaping their free play during breaks for both the treatment group and the control group. There were two 30-minute recordings at different times in the schoolyard. Darwish and his colleagues (2001) argued that in order to observe a number of behaviors and skills during free play, the observation should be a repetitive process in which 15 minutes of total observation time are used for each child, while McKevit and Elliot (2005), argued that over a period of several weeks five 20-minutes of total observation will be representative for the measurement of social behavior per student.

\section{FINDINGS}

The psychometric properties of the SSRS were analyzed as follows: considering the initial frequency, scores for each factor of social skills and behaviors were summed up separately and then divided by the number of questions in each factor of social skill or behavior problems. Finally, they were added in order to calculate the overall rating for each student. In order to investigate the normality of the values of each factor separately and in total, a normality test was performed. It was observed that the values of skewness and kurtosis of the samples were visibly $\neq 0$ for both measures and groups (TG, CG). In a normal distribution the specific statistical parameters were equal to 0 or nearby. Due to the non-normality of the distributions the Kolmogorov-Smirnov test was used. 
The averages and standard deviations of the degree of social skills and the behavior problems of students are represented in Table 2.

Table 2

Means and Standard Deviations of Social Skills and the Behavioral Problems of Students

\begin{tabular}{lcccc}
\hline & \multicolumn{2}{c}{ CONTROL GROUP } & \multicolumn{2}{c}{ TREATMENT GROUP } \\
\hline \multicolumn{1}{c}{ FACTORS } & TIME 1 & TIME 2 & TIME 1 & TIME 2 \\
\hline Cooperation & $15.4(3.4)$ & $15.4(3.4)$ & $13.1(5.0)$ & $17.0(3.5)$ \\
Assertion & $12.2(4.0)$ & $12.2(4.0)$ & $10.9(3.2)$ & $17.3(2.5)$ \\
Self-Control & $14.1(4.5)$ & $14.1(4.5)$ & $12.3(5.5)$ & $17.5(3.6)$ \\
Externalizing & $4.8(3.1)$ & $4.8(3.1)$ & $5.9(4.5)$ & $* 3.8(2.2)$ \\
Internalizing & $1.7(2.7)$ & $1.7(2.7)$ & $1.3(2.4)$ & $* 0.6(1.5)$ \\
Hyperactivity & $1.8(2.5)$ & $1.8(2.5)$ & $3.2(4.0)$ & $* 1.4(2.1)$ \\
Total & $50(7.2)$ & $50(7.2)$ & $46.7(5.8)$ & $57.5(5.1)$ \\
\hline
\end{tabular}

*Value reductions are associated with the improvement of behavioral problems and it refers to the reduction in the occurrence of certain undesirable behaviors.

It was verified that the average of the social skills of the students within the treatment group during the break was higher $(\mathrm{M}=57.5 \pm 5.1)$ in the second measurement than the average in the first measurement $(\mathrm{M}=46.7 \pm 5.8)$ (Table 2).

In order to check for any differences between the degree of social skills of the students during breaks in relation to their participation in a structured, playful activity program due to the non-normality of the distributions per factor and in total, the KolmogorovSmirnov test was used for two samples in order to test if they followed the same distribution. Originally, this was conducted for the samples between the treatment group and the control group during the first measurement. The maximum limit of difference between the cumulative distributions for a significance level $\mathrm{a}=0.05$ is do $=0.351$. It was found that the maximum difference $\mathrm{D}$ between the cumulative distributions of the two samples in total exceeded the boundary limit $(\mathrm{D}=0.367, \mathrm{D}>0.351)$ while the maximum difference $\mathrm{D}$ per agent did not exceed the threshold do.

The Kolmogorov-Smirnov test was then carried out between the two measurements for the treatment group, revealing that there is a statistically significant difference between the degree of social skills of the students and their participation in the program, in total $(\mathrm{D}=0.733, \mathrm{D}>0.351)$ and per factor: cooperation $(\mathrm{D}=0.5, \mathrm{D}>0.351)$, assertion $(\mathrm{D}=$ $0.867, \mathrm{D}>0.351)$, self-control $(\mathrm{D}=0.533, \mathrm{D}>0.351)$, while the factors externalizing ( $\mathrm{D}$ $=0.267, \mathrm{D}<0.351)$ internalizing $(\mathrm{D}=0.2, \mathrm{D}<0.351)$ and hyperactivity $(\mathrm{D}=0.267, \mathrm{D}$ $<0.351$ ) scores below the limit $\mathrm{D}=0.351$ are associated with the improvement of behavioral problems and they demonstrate the reduction in the occurrence of certain undesirable behaviors (Figure 1). In conclusion, it was observed that the intervention had positive effects on the treatment group, since the average performance of the students' social skills was greatly improved. On the other hand, there was no evidence of any change in the performance of the control group social skill's within the four-week period between measurements. 
Furthermore, by associating the degree of development in preschoolers' social skills from intervention during breaks in the schoolyard with their participation in organized out-of-school time physical activity, it was realized that there is no significant correlation $(\mathrm{D}=0.2727, \mathrm{D}<0.515)$. Similarly, this study detected no difference $(\mathrm{D}=$ $0.25, \mathrm{D}<0.497)$ on the degree of development of social skills between boys and girls except for the factor 'Hyperactivity'. Girls in this factor were slightly more improved than boys, however, this result was marginally statistically significant $(\mathrm{D}=0.5, \mathrm{D}>$ 0.497).

\section{DISCUSSION}

The effect of participation in a structured, playful activity programme on the social skills of pre-schoolers during breaks

The purpose of this study was to assess the social skills of kindergarten children (aged 5-6 years) and to investigate the effect of a playful activity structured program in the schoolyard during breaks on the development of students' social skills. Our findings verified the research hypothesis of the study and confirmed that a structured program of playful activities during breaks in the yard such as recyclables without any pedagogical value or re-organizing traditional games, positively affected the social skills of kindergarten students. Thus, it was found that students who participated in an intervention program which focuses on play for a four-week period, are significantly more socially adept during their play in the schoolyard than the students who followed the typical kindergarten program of spontaneous play in the schoolyard without receiving any intervention (placing inexpensive equipment and guidance from an adult).

According to the Kindergarten Curriculum Guide (Sotiropoulou-Zormpala et al., 2015) in Greek kindergartens free play is a period in the school schedule during which they interact with each other and utilize existing equipment, play freely in the yard or in the classroom depending on the weather conditions. During this period of time, the students have the opportunity to rest and develop their physical, social, emotional and cognitive skills (Lee et al., 2007; Pellegrini, 2006). However, Doliopoulou and Rizou (2012) argued that a significant proportion of teachers in Greek kindergartens confirm children's inability to initiate organized team games, through which social skills are developed, as well as preschoolers' aggressive behavior, as a consequence of the modern lifestyle.

Most children learn to acquire social skills through interaction with others: peers, family, friends and other adults (Barone and Lionetti, 2012; McGarth and Francey, 1991). However, in order to achieve the maximum effect, the development of social skills seems to be supported through a process in which an adult organizes methodological interventions developmentally appropriate for each age group of children (DuPaul \& Eckert, 1994; McGarth \& Francey, 1991). A number of previous studies argued with the positive influence of the structured rest hour, when games are organized by educators so that they can enhance the participation and interaction of young children in playful activities (McKenzie and Kahan, 2008; Parsad and Lewis, 2006; Zygmunt-Fillwalk and Bilello, 2005). 
In the literature, numerous investigations which studied the effect of certain program on social skills of preschool children have already been identified (Cartledge and Milburn, 1995; Kavale et al, 1997; McGrath and Noble, 2010) and they draw the same conclusions with the present study. Furthermore, an important reference point for this research is the planning of the program which renders play as the main social skill training tool (Rosenthal \& Gatt, 2010). Although other studies have emphasized on cognitive development by using different methodological designs which had high cost and required a lot of implementation time (Bryant et al, 1999). In addition, it was required by kindergarten teachers to get additional training in order to be involved in this process (Bryant et al, 1999).

The findings of the present study are quite important for kindergartens as they may motivate kindergarten teachers to implement similar program in the future, utilizing free play in the schoolyard and thus, rendering it an important practical value in preschool education. Most importantly, the playful activity program of this survey does not contain a specific structured curriculum for kindergarten students but it's a stimulus tool that preschool teachers can adapt to the specific needs of the addressed students population. This current program is an experiential procedure rather than an academic teaching method both for preschoolers and for teachers who are involved as mediators of the playful intervention.

\section{The effect of participation in OST physical activity on the social skills of preschoolers during breaks}

By associating the degree of development in preschoolers' social skills from intervention during breaks in the schoolyard with their participation in organized out-ofschool time (OST) physical activity, it was realized that there is no significant correlation $(\mathrm{D}=0.2727, \mathrm{D}<0.515)$ which means that the children who participated in any organized physical activity outside the school had not improved their social skills in kindergarten more than their classmates who did not participate in OST physical activity. This result likely arise due to the age factor, as preschoolers primarily depend on their parents for the choice of activities they are going to take part in. Also, their preference in certain activity may be due to the engagement of their classmates and not to their desire to engage in activity itself (Ladd, and Hart, 1992; Bailey, Cope and Pearce, 2013), leading them in many times to have a sense of boredom and give up the activity (Duda and Ntoumanis, 2005). That said, changing sports activities in a short period of time that is very common in this age group makes it difficult for any development of learning context of social skills due to the limited stay of infants in these sports activities (Trudeau and Shephard, 2008). However, in Greece the organization which offers any kind of physical activity out of school schedule, are more related to learn a specific content of sport or game than to enhance directly the social skills of the participants.

From the other point of view, a playful activity structured program in the schoolyard during breaks under the teachers' guidance can help children to interact, to externalize themselves, to be accepted and imitate appropriate behaviours enhancing the 
opportunity for social acceptance among students as they take part in games and group activities, increase their chance of success in community.

Eventually, during the communication process through play tasks such as dynamic group, motivational activities as well as the organisation and managing of the play area by the teacher, could provide a frame for a strong dynamics between the group and the social relations among the students (Valera-Tomás et al., 2010).

\section{The effect of gender on the social skills of preschoolers during breaks}

According to the finding of this study, no difference $(\mathrm{D}=0.25, \mathrm{D}<0.497$ ) have found on the degree of development of social skills between boys and girls except for the factor 'Hyperactivity'. Girls in this factor were slightly more improved than boys, however, this result was slightly statistically significant $(\mathrm{D}=0.5, \mathrm{D}>0.497)$. Previous studies (Coolahan et al., 2000; Mendez et al., 2002; Vahedi et al., 2012), have recorded significant differences in the social skills between the two genders, argued that boys are more physically active, more committed to competitive activities that involve high risk and exhibit more anger and aggression than girls. On the other hand, girls are friendlier, prefer to play in pairs or enjoy the company of their kindergarten teachers, who are usually female, and they seem to be more eager to develop their social skills and control their behavior in order to avoid their teachers' criticism (Brown, and Freeman, 2001). In accordance with our results are the finding powered by Zachopoulou and her colleagues (2004) in a study which was carried out in 16 Greek kindergartens. It was found that boys and girls showed nearly similar abilities in communicating, cooperating and sharing toys and had the similar potential with regard to the social skills between the two genders.

\section{CONCLUSION}

The purpose of this study was to assess the social skills of kindergarten children (aged 5-6 years) and to examine the effect of a playful activity structured program on the development of students' social skills during break time in the schoolyard. Concluding, our results demonstrated that a structured program of playful activities during breaks in the schoolyard such as recyclables without any pedagogical value or re-organizing traditional games for a 4-week period affects the social skills of kindergarten students. The conclusions drawn from current study concerning the intervention methods, such as the positive effect of the mediating role of adults in children's free play, come to an agreement with a number of aforementioned studies. These conclusions were drawn from the analysis of data, collected by a social skills rating system and videotaped recordings of 60 students from two different Greek kindergartens. Subsequent investigations with larger sample are more likely to confirm or revise some of these conclusions. Moreover, future research could possibly study the effect of certain cultural factors (religion, ancestry, language) on the degree of development of social skills in preschool children. It is obvious that without appropriate interventions in early childhood education, young children will be at risk of undergoing negative experiences within peer groups, which in turn will result in unhealthier adults. Preschoolers through playing and being guided by adults not only practice their social skills but also given the 
opportunity for further development. In this way, children will be able to socialize, behave in a way that is socially acceptable and learn how to be responsible. Play is an important tool which contributes to personality development, social development and mental health through which, children gain life experiences that will help them to coexist with other people.

Future studies should continue to investigate: (a) social skills of preschoolers out of kindergarten framework, through their participation in a structured playful program at school with the involvement of their parents, (b) the use of an additional measurement tool as a scale model for assessing the social skills of young children, (c) the participation of a larger sample of preschool children for drawing safer conclusions, (d) preschoolers' social skills considering socio-cultural differences between the individuals.

\section{REFERENCES}

Barone, L., \& Lionetti, F. (2012). Attachment and social competence: A study using MCAST in low-risk Italian preschoolers. Attachment \& Human Development, 14(4), 391-403.

Bell, J. (2005). Doing your Research Project. A Guide for first-time Researchers in Education, Health and Social Science (4th Edition). Buckinghamshire, Open University Press.

Bhavnagri, N. P., \& Parke, R. D. (1991). Parents as direct facilitators of children's peer relationships: Effects of age of child and sex of parent. Journal of Social and Personal Relationships, 8(3), 423-440.

Bjorklund, D. F., \& Brown, R. D. (1998). Physical play and cognitive development: Integrating activity, cognition, and education. Child Development, 69(3), 604-606.

Brown, M. H., \& Freeman, N. K. (2001). "We don't play that way at preschool": The moral and ethical dimensions of controlling children's play. In Early education and care, and reconceptualizing play (pp. 259-274). Emerald Group Publishing Limited.

Bryant, D., Herndon Vizzard, L., Willoughby, M., \& Kupersmidt, J. (1999). A review of interventions for preschoolers with aggressive and disruptive behavior. Early Education and Development, 10(1), 47-68.

Bodrova, E., \& Leong, D. J. (2015). Vygotskian and Post-Vygotskian Views on Children's Play. American Journal of Play, 7(3), 371-388.

Buckingham, D. (2000). After the Death of Childhood: growing up in the age of Multimedia.

Cartledge, G., \& Milburn, J. F. (1995). Teaching social skills to children and youth: Innovative approaches. Allyn \& Bacon. 
Coolahan, K., Fantuzzo, J., Mendez, J., \& McDermott, P. (2000). Preschool peer interactions and readiness to learn: Relationships between classroom peer play and learning behaviors and conduct. Journal of Educational Psychology, 92(3), 458.

Corsaro, W. A., \& Molinari, L. (2005). I compagni: Understanding children's transition from preschool to elementary school. Teachers College Press.

Darwish, D., Esquivel, G. B., Houtz, J. C., \& Alfonso, V. C. (2001). Play and social skills in maltreated and non-maltreated preschoolers during peer interactions tr 1. Child abuse \& neglect, 25(1), 13-31.

Devine, D. (2002). Children's citizenship and the structuring of adult-child relations in the primary school. Childhood, 9(3), 303-320.

Doliopoulou, E., \& Rizou, C. (2012). Greek kindergarten teachers' and parents' views about changes in play since their own childhood. European Early Childhood Education Research Journal, 20(1), 133-147.

Duda, J. L., \& Ntoumanis, N. (2005). After-school sport for children: Implications of a task-involving motivational climate. Organized activities as contexts of development: Extracurricular activities, after-school and community programs, 311-330.

DuPaul, G. J., \& Eckert, T. L. (1994). The effects of social skills curricula: Now you see them, now you don't. School Psychology Quarterly, 9(2), 113.

Fox, C. L., \& Boulton, M. J. (2005). The social skills problems of victims of bullying: Self, peer and teacher perceptions. British Journal of Educational Psychology, 75(2), 313-328.

Gerrish, K., \& Lacey, A. (2010). The research process in nursing. John Wiley \& Sons.

Gouley, K. K., Brotman, L. M., Huang, K. Y., \& Shrout, P. E. (2008). Construct validation of the social competence scale in preschool-age children. Social Development, 17(2), 380-398.

Grammatikopoulos, V. (2012). Integrating program theory and systems-based procedures in program evaluation: A dynamic approach to evaluate educational programs. Educational Research and Evaluation, 18(1), 53-64.

Greene, J. O. (2003). Models of adult communication skill acquisition: Practice and the course of performance improvement. In Handbook of communication and social interaction skills (pp. 69-110). Routledge.

Gresham, F. M. \& Elliott, S. N. (1990). Social skills rating system. Cedar Pines, MN: American Guidance Service.

Han, S. S., Catron, T., Weiss, B., \& Marciel, K. K. (2005). A teacher-consultation approach to social skills training for pre-kindergarten children: Treatment model and short-term outcome effects. Journal of Abnormal Child Psychology, 33(6), 681-693.

Hughes, B. (2003). Play Deprivation: Facts and Interpretations. Play Wales. 
Kavale, K. A., Mathur, S. R., Forness, S. R., Rutherford, R. B., \& Quinn, M. M. (1997). Effectiveness of social skills training for students with behavior disorders: A metaanalysis. Advances in learning and behavioral disabilities, 11, 1-26.

Kokkinos, C. M., \& Antoniadou, N. (2013). Cyber-bullying and cyber-victimization in children and adolescents: Incidence and risk factors. Preschool and Primary Education, 1, 138-169.

Ladd, G. W., \& Hart, C. H. (1992). Creating informal play opportunities: Are parents' and preschoolers' initiations related to children's competence with peers?. Developmental Psychology, 28(6), 1179.

Langeveld, J. H., Gundersen, K. K., \& Svartdal, F. (2012). Social competence as a mediating factor in reduction of behavioral problems. Scandinavian Journal of Educational Research, 56(4), 381-399.

Lee, S. M., Burgeson, C. R., Fulton, J. E., \& Spain, C. G. (2007). Physical education and physical activity: results from the School Health Policies and Programs Study 2006. Journal of school health, 77(8), 435-463.

MacDougall, C., Schiller, W., \& Darbyshire, P. (2004). We have to live in the future. Early Child Development and Care, 174(4), 369-387.

McCambridge, T. M., Bernhardt, D. T., Brenner, J. S., Congeni, J. A., Gomez, J. E., Gregory, A. J., ... \& Small, E. W. (2006). Active healthy living: prevention of childhood obesity through increased physical activity. Pediatrics, 117(5), 1834-1842.

McGrath, H., \& Francey, S. (1991). Friendly kids, friendly classrooms. Longman.

McGrath, H., \& Noble, T. (2010). Supporting positive pupil relationships: Research to practice. Educational and Child Psychology, 27(1), 79.

McKenzie, T. L., \& Kahan, D. (2008). Physical activity, public health, and elementary schools. The Elementary School Journal, 108(3), 171-180.

McKevitt, B. C., \& Elliott, S. N. (2005). Observations and ratings of preschool children's social behavior: Issues of representativeness and validity. Psychology in the Schools, 42(1), 13-26.

Mendez, J. L., McDermott, P., \& Fantuzzo, J. (2002). Identifying and promoting social competence with African American preschool children: Developmental and contextual considerations. Psychology in the Schools, 39(1), 111-123.

Miller, E., \& Almon, J. (2009). Crisis in the kindergarten: Why children need to play in school. Alliance for Childhood (NJ3a).

Moss-Morris, R., Weinman, J., Petrie, K., Horne, R., Cameron, L., \& Buick, D. (2002). The revised illness perception questionnaire (IPQ-R). Psychology and health, 17(1), 116. 
Parsad, B., \& Lewis, L. (2006). Calories In, Calories Out: Food and Exercise in Public Elementary Schools, 2005. ED TAB. NCES 2006-057. National Center for Education Statistics.

Pellegrini, A. D. (2006). Recess: Its role in education and development. Psychology Press.

Rasberry, C. N., Lee, S. M., Robin, L., Laris, B. A., Russell, L. A., Coyle, K. K., \& Nihiser, A. J. (2011). The association between school-based physical activity, including physical education, and academic performance: a systematic review of the literature. Preventive medicine, 52, S10-S20.

Rosenthal, M. K., \& Gatt, L. (2010). 'Learning to Live Together': training early childhood educators to promote socio-emotional competence of toddlers and pre-school children. European Early Childhood Education Research Journal, 18(3), 373-390.

Rosenthal, M. K. (2003). Quality in early childhood education and care: A cultural context. European Early Childhood Education Research Journal, 11(2), 101-116.

Scarlett, W. G., Al-Solaim, L., Naudeau, S., Salonius-Pasternak, D., \& Ponte, I. (2005). Children's play. Sage.

Schneider, B. H., Richard, J. F., Younger, A. J., \& Freeman, P. (2000). A longitudinal exploration of the continuity of children's social participation and social withdrawal across socioeconomic status levels and social settings. European Journal of Social Psychology, 30(4), 497-519.

Sibley, B. A., \& Etnier, J. L. (2003). The relationship between physical activity and cognition in children: a meta-analysis. Pediatric exercise science, 15(3), 243-256.

Smith, A. L. (2003). Peer relationships in physical activity contexts: A road less traveled in youth sport and exercise psychology research. Psychology of Sport and Exercise, $4(1), 25-39$.

Sotiropoulou-Zormpala, M., Trouli, K., \& Linardakis, M. (2015). Arts education offered by Greek Universities to future pre-school and primary school teachers. Preschool and Primary Education, 3(1), 34-52.

Stagnitti, K. (2004). Understanding play: The implications for play assessment. Australian Occupational Therapy Journal, 51(1), 3-12.

Trevlas, E., Matsouka, O., \& Zachopoulou, E. (2003). Relationship between playfulness and motor creativity in preschool children. Early Child Development and Care, 173(5), 535-543.

Trudeau, F., \& Shephard, R. J. (2008). Physical education, school physical activity, school sports and academic performance. International Journal of Behavioral Nutrition and Physical Activity, 5(1), 10

Vahedi, S., Farrokhi, F., \& Farajian, F. (2012). Social competence and behavior problems in preschool children. Iranian journal of psychiatry, 7(3), 126. 
Valera Tomás, S., Ureña Ortín, N., Ruiz Lara, E., \& Alarcón López, F. (2010). La enseñanza de los deportes colectivos en Educación Física en ESO.

Zachopoulou, E., Trevlas, E., \& Tsikriki, G. (2004). Perceptions of gender differences in playful behaviour among kindergarten children. European Early Childhood Education Research Journal, 12(1), 43-53.

Zygmunt-Fillwalk, E., \& Bilello, T. E. (2005). Parents' victory in reclaiming recess for their children. Childhood Education, 82(1), 19-23. 